\title{
TRANSIÇÃO ENERGÉTICA: ENQUADRAMENTO E DESAFIOS
}

\section{ENERGY TRANSITION: FRAMEWORK AND CHALLENGES}

Filipe Matias Santos ${ }^{1}$

RESUMO: O presente artigo propóe-se apresentar uma visăo global do fenómeno da eletrificaçăo da economia, no quadro da alteraçăo da matriz energética e da promoçâo das fontes renováveis, assinalando os desafios que lhe sâo inerentes.

Palavras-chave: Energia. Transiçâo Energética. Regulaçăo. Apoio às Renováveis. Trilema Energético.

ABSTRACT: This article purports to provide a global overview of the electrification of the economy, in the framework of the energy matrix change and the promotion of renewables, underlining the inherent challenges.

Keywords: Energy. Energy Transition. Regulation. Renewables Support. Energy Trilemma.

\section{INTRODUÇÃO}

A transiçăo energética, um outro nome para a eletrificaçăo da economia, traz novos e relevantes desafios ao setor energético².

Depois de décadas de predominância do petróleo, o setor energético move-se dos hidrocarbonetos para os eletróes (Royal Dutch Shell and Total flirt..., 2018; TRICKS, 2018). Vários indicadores apontam para um substancial crescimento da eletricidade no mix energético, capaz de substituir a hegemonia do petróleo ${ }^{3}$.

A inovaçâo tecnológica e as políticas públicas de apoio às fontes de energia renováveis criaram condiçóes para que a eletricidade aumentasse significativamente o seu papel nos mercados da energia (PÉREZ-ARRIAGA; KNITTEL, 2016, pp. 9-12).

Por sua vez a eletricidade é especialmente versátil, podendo ser utilizada para múltiplos fins, como a introduçáo dos veículos elétricos tem demonstrado. E, sobretudo, a eletrificaçấo da economia contribui decisivamente para a descarbonizaçâo da sociedade, traz maior segurança de abastecimento a países sem abundância de recursos fósseis endógenos e é, hoje, inclusivamente, cada vez mais competitiva. Este artigo procura mapear o efeito da substituiçâo das fontes de energia existentes por outras formas de energia e os desafios inerentes que resultam numa alteraçâo do quadro energético global.

\section{TRANSIÇÃO ENERGÉTICA}

1 Mestre em Ciências Jurídico-Empresariais pela Nova de Lisboa, Diretor dos Serviços Jurídicos da Entidade Reguladora dos Serviços Energéticos (ERSE). As opiniōes e interpretaçôes expressas no presente documento săo pessoais e năo podem ser atribuídas à ERSE. Advogado.FSantos@erse.pt 


\subsection{A PERSPETIVA DO FIM DA "ERA DO PETRÓLEO"}

Desde a revoluçăo industrial que os combustíveis fósseis fazem mover as economias. Entre outras commodities existentes, o petróleo exerceu crescentemente um papel central, sendo considerado um dos mais importantes recursos naturais existentes. De facto, comparando com outros recursos fósseis, tais como o carvâo e o gás natural, o petróleo é mais potente, fácil de transportar, armazenar e capaz de ser transformado em diferentes produtos (combustível e produtos).

A denominada "era do petróleo" foi caracterizada pela concentraçâo e por geopolítica. A Standard Oil Company, fundada por John D. Rockefeller, uma das primeiras e maiores empresas multinacionais do mundo, controlou inicialmente o mercado de produtos petrolíferos (INKPEN; MOFFETT, 2011, pp. 3-6, 53-78). ${ }^{4}$ Depois de 14 de maio de 1911, quando o US Supreme Court decidiu a dissoluçăo da Standard Oil Company por considerar que estava em violaçâo das regras de concorrência (The Sherman Antitrust $A c t^{5}$ ), a indústria petrolífera foi fortemente influenciada (desde meados de 1940 até meados de 1970) pelas conhecidas "seven sisters", ou seja, as companhias petrolíferas multinacionais do "Consórcio do Irâo". Apenas quatro dessas empresas ainda subsistem (BP, ExxonMobil, Chevron (Texaco) e Royal Dutch Shell), competindo, principalmente, contra o OPEC (cartel de protrolíferas) e contra algumas das maiores companhias petrolíferas detidas por Estados (FATTOUH; POUDINEH; WEST, 2018; INKPEN; MOFFETT, 2011, pp. 69, 367, 442-444).

A relevância do petróleo estendeu-se ao mundo jurídico e levou à materializaçâo de uma doutrina que invoca a existência da "lex petrolea"6 como um regime distinto e distintivo que regula (ou que pretende regular) as relaçóes e a transiçâo petrolífera internacional, aplicável juntamente com as leis nacionais e internacionais.

Contudo, năo é um grande risco ditar o fim da "era do petróleo", tal como a conhecemos. Com efeito, nâo obstante o petróleo evidenciar resiliência - tendo sobrevivido à energia atómica - é mais provável que atualmente estejamos a viver uma transiçấo energética (TRICKS, 2018; Royal Dutch Shell and Total flirt..., 2018). Devido a várias razóes, verdadeiros game changers, os mercados energéticos estăo a mudança acelerada. As fontes de energia existentes estâo a ser substituídas por outras formas de energia, alterando totalmente o quadro energético global.

Como consequência e sem que isso constitua uma surpresa, um crescente número de companhias petrolíferas está a rever e a relançar as suas estratégias de negócio e de comunicaçấo (para ficarem mais "verdes") e a orientar o seu negócio para a eletricidade7, sem prejuízo de, num jogo duplo, manterem ou até aumentarem os seus

4 Outro fato interessante é que a Standard Oil foi uma das primeiras empresas que começaram a contratar advogados em seus negócios (advogados internos), estabelecendo um dos primeiros departamentos jurídicos - cf. EUROPEAN COMPANY LAWYERS ASSOCIATION (2013).

5 Cf. WILGUS (1911).

6 Sobre a existência da "lex petrolea", numa visăo crítica: DAINTITH (2017, pp. 1-13).

7 A petrolífera norueguesa "Statoil" mudou a firma para "Equinor" e passou a explorar fontes renováveis (vento e sol). Também a empresa dinamarquesa "Dong Energy" alterou a denominaçâo social para Ørsted. A empresa gasista "Gas Natural Fenosa" denomina-se, presentemente, de "Naturgy". Empresas petrolíferas como a Total, a Repsol, a Shell ou a CEPSA estăo a desenvolver recursos renováveis e/ou entraram no fornecimento de eletricidade. 
investimentos no upstream ${ }^{8}$.

Năo subestimamos que o oil \& gas continuará a desempenhar um papel relevante. O ponto de partida náo permite que algo de diferente seja sequer pensável: na matriz energética mundial, tal como na europeia, o oil \& gas continua a representar bem mais de $50 \%$ do consumo de energia. O contributo destes vetores energéticos permanecerá, sobretudo nos sub-setorores dos transportes e do aquecimento e arrefecimento. Simplesmente, a tendência que parece imparável, pelo menos na Europa, é a de uma certa inversáo no peso histórico relativo de cada vetor energético no mix energético, com preponderância crescente para a eletricidade produzida a partir de fontes renováveis.

\subsection{O APOIO ÀS RENOVÁVEIS NO CONTEXTO EUROPEU}

No contexto Europeu o apoio às energias renováveis, entendidas como novas fontes (alternativas às convencionais), na sequência das crises do petróleo ${ }^{9}$, tem sido justificado no universo europeu por razôes de ordem energética, geopolítica e ambiental, dada a instrumentalidade destas fontes alternativas (SILVA, 2011, pp. 99-103) para a garantia de abastecimento e inerente reduçâo da dependência face aos países produtores, bem como o seu contributo para a sustentabilidade em virtude da inerente reduçấo das emissôes de $\mathrm{CO}_{2}$ (descarbonizaçăo), evitando a vaticinada tragedy of the commons (DIAS, 2008, pp. 140-141; HARDIN, 1968; PÉREZ-ARRIAGA, 2013, pp. 62, 443-479)

É incontroverso que a Europa dispōe de recursos fósseis manifestamente insuficiente para as suas necessidades e, também, que a sua utilizaçăo é extremamente poluente. Neste contexto, as advertências relativas à segurança do abastecimento e às alteraçóes climáticas globais têm um papel importante na promoçâo das energias renováveis, de forma a atingir a descarbonizaçâo. Estas preocupaçôes de segurança de abastecimento e de sustentabilidade ambiental correspondem, mesmo, a dois dos três objetivos do conhecido energy trilemma ${ }^{10}$ (MACNAUGHTON, 2015).

Assim, o primeiro Livro Verde sobre a implementaçăo do mercado interno da energia ${ }^{11}$, que remota a 1998, realçava como um dos três vetores principais que fosse alcançado um equilíbrio satisfatório entre a competitividade da energia e as questóes ambientais (EIKELAND, 2004). E no plano do direito positivo, desde entăo, é visível a

8 A Bloomberg New Energy Finance (BNEF) prevê que o uso de recursos fósseis para produçăo de eletricidade atinja o valor máximo em 2025 e decresça inexoravelmente depois disso (PEREZ-ARRIAGA; KNITTEL, 2016, pp. 8).

9 A primeira, em 1973, desencadeada num contexto de deficit de oferta que teve como pano de fundo o conflito israelo-árabe (Guerra do Yom Kippur) e o posicionamento da Organizaçấo dos Países Produtores de Petróleo (OPEP) face à posiçấo tomada pelos Estados Unidos da América. A segunda, já nos anos 80, no contexto da guerra entre dois dos maiores produtores de petróleo, o Irăo e o Iraque, o que conduziu à reduçăo da produçấo e, consequentemente, ao aumento dos preços. Apenas no final da década de 1980 a promoçăo da integraçấo dos mercados energéticos nacionais num verdadeiro mercado interno da energia passou a estar na agenda do Conselho da Uniăo Europeia (ANDRADE; MARCOS, 2013, pp. 26-34; INOCÊNCIO, 2015; SANTOS, 2016, pp. 33-55).

10 Sobre o aumento crescente do foco da undústria de oil \& gas na segurança e ambiente vd. INKPEN; MOFFETT (2011, pp. 157-158, 160-161, 289, 394, 428-451, 463, 465, 536-553).

$11 \mathrm{COM} / 88 / 238$. 
influência política dos movimentos ambientalistas iniciada na década de 90 (Rio, 1992 e Quioto, 1997). A aposta passou pelo desenvolvimento de fontes de energia renovável na produçâo de eletricidade (Diretiva 2001/77/CE, de 27 de setembro), bem como pelos processos de co-geraçấo (Diretiva 2004/8/CE, de 11 de fevereiro) ${ }^{12}$ e teve reflexos visíveis no denominado "segundo pacote" energético, de 2003, que integra as Diretivas n. ${ }^{\circ}$ 2003/54/CE e n. ${ }^{\circ}$ 2003/55/CE, ambas do Parlamento Europeu e do Conselho, de 26 de junho, que estabelecem regras comuns para o mercado interno da eletricidade e do gás natural ${ }^{13}$.

Assim, no início do virar do novo século foi aprovada a primeira Diretiva relativa à promoçấo da eletricidade produzida a partir de fontes de energia renováveis no mercado. A Diretiva n. ${ }^{\circ}$ 2001/77/CE, do Parlamento Europeu e do Conselho, de 27 de setembro de 2001, que veio exigir metas nacionais, ainda que indicativas, posteriormente revogada pela Diretiva 2009/28/CE, do Parlamento Europeu e do Conselho, de 23 de abril de 2009. Esta última Diretiva instituiu a obrigatoriedade dos Estado-membro aprovarem Planos Nacionais de Açâo para as Energias Renováveis (art. $4 .^{\circ}$ da Diretiva n. ${ }^{\circ}$ 2009/28/CE, de 23 de abril ${ }^{14}$ ).

Neste novo enquadramento, em nome da descarbonizaçâo, foram permitidas ajudas de Estado às renováveis, passando o Estado a assumir um papel de Estadoincentivador e facilitador. Aos produtores de energia elétrica de fonte renovável, em regime especial, foram atribuídos os direitos de prioridade de injeçăo na rede e preços administrativos garantidos (através de um esquema feed in tariffs, também conhecido pelo acrónimo FIT, que historicamente se traduz num sobrecusto a pagar por todos os consumidores independentemente do seu comercializador) ${ }^{15}$.

Vale isto por dizer que foi reconhecida a necessidade do apoio público às fontes de energia renováveis, balizado também pelas Orientaçôes para apoio às Renováveis de 2001, posteriormente, de 2008, mais recentes revistas em 201416. Tal orientaçáo verifica-se também em matéria de auxílios estatais à proteçâo do ambiente, que, entre outras opçóes, têm em conta a necessidade de internalizar os custos externos da produçâo de eletricidade.

Num quadro de escassez de recursos endógenos, o diagnóstico da Comissăo Europeia continuou a apontar para que a Uniăo Europeia nâo tem conseguido dar uma resposta suficiente à sua excessiva dependência face ao exterior em matéria energética, mantendo a posiçăo de maior importador de energia do mundo, onde se praticam preços grossistas da eletricidade e do gás, respetivamente, 30\% e 100\% mais elevados do que nos Estados Unidos ${ }^{17}$. A consciência do diagnóstico faz com que a promoçăo das

12 Vd. SILVA (2011, pp. 80-81).

13 Sobre a evoluçăo legislativa da energia no contexto europeu vd. ANDOURA; VINOIS (2015); JOHNSTON; BLOCK (2012); JONES (2006); LEAL-ARCAS; RIOS (2015); SANTOS (2016).

14 Vd. GOMES (2008); GOMES; ANTUNES (2011); HANCHER; HAUTECLOCQUE; SADOWSKA (2015).

15 Em 2014, segundo dados da Agência Internacional da Energia (AIE) o apoio mundial às fontes renováveis atingiu 112 mil milhōes de dólares.

16 2014/C 200/01.

17 A Uniâo Europeia importa 53\% da sua energia, com um custo anual de cerca de 400 mil milhôes de euros e seis dos seus Estados-Membros dependem de um fornecedor externo único (Rússia) para todas as suas importaçōes de gás; $75 \%$ do parque habitacional europeu é ineficiente do ponto de vista energético; $94 \%$ dos 
fontes de energia renováveis (a par da eficiência energética e do relançamento do comércio de licenças de emissăo), integrasse o objetivo estratégico da Uniâo da Energia de continuar a abandonar uma economia alimentada a combustíveis fósseis.

Na sequência do Acordo de Paris, a iniciativa política de "Uniâo Energética" levou a Uniâo Europeia à aprovaçấo o novo "Pacote Energia Limpa" da Uniăo Europeia ${ }^{18}$, que inclui a recentemente publicada Diretiva (UE) n. ${ }^{\circ}$ 2018/2001 do Parlamento Europeu e do Conselho de 11 de dezembro de 2018, publicada no dia 21 de dezembro, que veio reformular a Diretiva 2009/28/CE do Parlamento Europeu e do Conselho de 23 de abril de 2009, relativa à promoçâo da utilizaçâo de energia proveniente de fontes. Através deste novo Pacote, a Uniâo Europeia estabeleceu metas para 2030 de (i) 32\% de quota de energia proveniente de fontes renováveis no consumo final bruto, $14 \%$ no setor dos transportes (ii) 32,5\% de reduçăo do consumo de energia, (iii) 40\% de reduçáo das emissóes de gases com efeito de estufa relativamente aos níveis de 1990, e (iv) 15\% de interligaçóes elétricas.

A eletrificaçâo é, por sua vez, permitida pelos apoios concedidos que permitiram e incentivaram determinantemente o desenvolvimento de tecnologias associadas à geraçăo da eletricidade renovável. Para tanto pesaram, năo só as mencionadas razóes ambientais, mas também, as preocupaçôes com a segurança do abastecimento.

Dada a ausência de recursos endógenos em abundância, a aposta nas renováveis foi sempre vista na Europa, como noutras geografias de iguais características, como uma forma de reduzir a dependência energética face a Estados terceiros.

\subsection{O DESENVOLVIMENTO TECNOLÓGICO}

O terceiro objetivo do energy trilemma ${ }^{19}$ (MACNAUGHTON, 2015), a competividade, foi alcançado pelo desenvolvimento tecnológico que beneficiou dos apoios concedidos às fontes de energia renováveis. Com efeito, as tarifas de venda elevadas recebidas

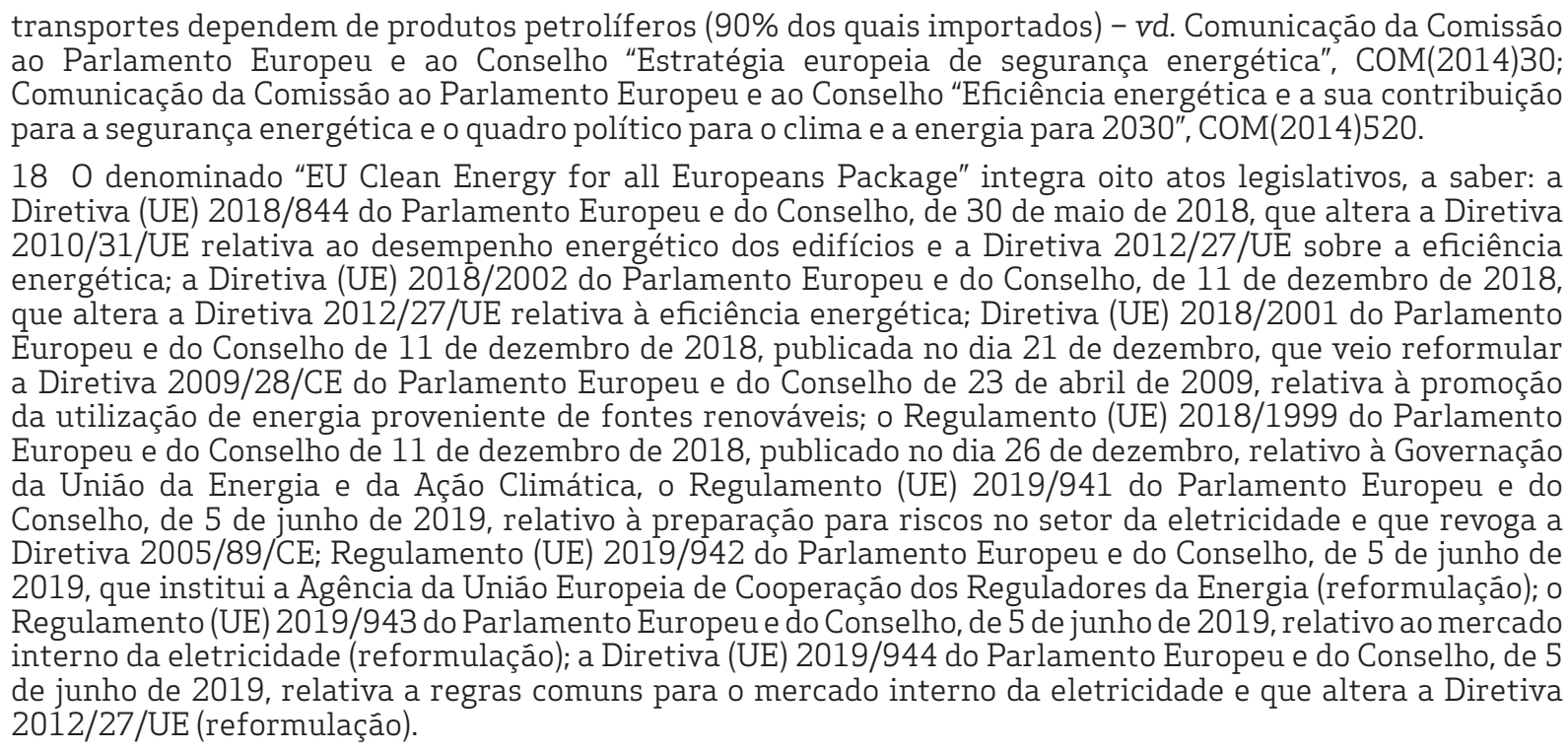
19 Sobre o aumento crescente do foco da indústria de oil \& gas na segurança e ambiente vd. INKPEN; MOFFETT (2011, pp. 157-158, 160-161, 289, 394, 428-451, 463, 465, 536-553). 
pelos produtores renováveis permitiram a aposta nestas tecnologias.

O estado atual de maturidade das tecnologias associadas à geraçâo da eletricidade renovável, pela sua eficiência e competitividade, é um ativo que em muito contribui para a eletrificaçăo ${ }^{20}$. Este fator é, ainda, reforçado pela expansăo do mercado de gás natural liquefeito (GNL) ${ }^{21}$ e do shale gas, que também săo utilizáveis na produçấo de energia elétrica através de centrais de ciclo combinado (CCGT) ${ }^{22}$.

Tudo isto ofereceu uma competitividade adicional à eletricidade face a outros vetores energéticos. $\mathrm{O}$ que permite tanto a um produtor de eletricidade a partir de fontes renováveis competir economicamente com os produtores que utilizavam fontes convencionais, como aumentou decisivamente a competitividade da energia elétrica de entre os diferentes vetores energéticos.

Outra consequência prende-se com a mudança de paradigma da produçâo. Historicamente, o sistema elétrico era caracterizado por grandes produtores que injetavam a energia produzida em muito alta tensăo. $O$ que deu lugar à produçăo, em menor escala, que injeta a energia um pouco por toda a rede, incluindo a rede de distribuiçăo nos seus diferentes níveis de tensâo. $O$ advento da integraçăo das várias fontes de energia renovável trouxe, portanto, um aumento de produçâo através de geradores de escala reduzida. É a chamada produçăo descentralizada, que inclui năo só os parques eólicos e solares de relativa pequena dimensăo (ao ponto de injetarem na rede de distribuiçâo, e nâo na de transporte), mas também os pequenos geradores ligados diretamente aos consumidores (de que săo exemplos os painéis solares que produzem energia para o proprietário de uma habitaçăo).

A perspetiva de consumidores com maior capacidade de investimento poderem vir a ser fornecidos de eletricidade sem rede de energia elétrica (off-grid), através de equipamentos de geraçâo próprios e apoiados em baterias, parece, hoje, menos distante. A possibilidade de os consumidores, isolada ou coletivamente, produzirem para autoconsumo e, com isso, diminuírem a sua dependência face à rede elétrica é uma realidade tecnológica (CEER, 2019). A rede elétrica pode passar, para estes, a funcionar como backup ${ }^{23}$. As energy communities, denominadas de comunidades de cidadâo de energia ${ }^{24}$ e de comunidades de energia renovável ${ }^{25}$, pelas novas Diretivas do mercado interno e da promoçăo da utilizaçăo de energia proveniente de fontes renováveis

200 preço das tecnologias de produçăo eóliça e solar decresceu 40 a 60\% entre 2008 e 2014, e a iluminaçấo LED cerca de 90\% no mesmo período - cf. PÉREZ-ARRIAGA; KNITTEL (2016, pp. 10).

21 De acordo com os dados da Bloomberg, o crescimento da procura de gás natural liquefeito aumentou 25 milhôes de toneladas (Mmtpa) em 2017 para um máximo 285 Mmtpa, registando o maior crescimento anual desde o incidente de Fukushima, em 2011, que levou ao aumento das importaçóes do Japâo.

22 Alguns dos maiores países produtores de combustíveis, tal como a China, à sua maneira, estăo a tentar fazer a transiçáo de uma economia de energia intensiva para uma economia orientada para os serviços (o que significa um menor consumo de energia) e estăo a utilizar renováveis e gás (nomeadamente Gás de xisto shale gas - e a construir um gasoduto oriundo da Rússia).

23 As comunidades locais de energia que operam uma rede devem ser regulamentadas como DSO e ter as mesmas obrigaçôes na prestaçáo de serviços e nos direitos dos consumidores - cf. CEER (2017).

24 Artigo 16. ${ }^{\circ}$ da Diretiva (UE) 2019/944 do Parlamento Europeu e do Conselho, de 5 de junho de 2019, relativa a regras comuns para o mercado interno da eletricidade.

25 Artigo 22. ${ }^{\circ}$ da Diretiva (UE) 2018/2001 do Parlamento Europeu e do Conselho de 11 de dezembro de 2018, publicada no dia 21 de dezembro, relativa à promoçâo da utilizaçăo de energia proveniente de fontes renováveis. 
energias renováveis, respetivamente, vêm dar um impulso significativo na promoçâo destas novas realidades.

Estamos, portanto, perante a introduçâo conceptual de uma inovaçấo: casos de ténue distinçăo entre a procura e a oferta, uma vez que parte dos tradicionais consumidores sâo, agora, também, produtores - prosumers (IEA, 2017, pp. 89-100). Podem nâo só produzir para consumo próprio, como para vender através da injeçăo na rede. $O$ que é potenciado pela inteligência artificial (cognitive computing, big data, data exchange, cloud computing), e a internet das coisas (the internet of things).

Paralelamente, a indústria dos transportes, que assume uma relevante interceçâo com o setor energético, era tradicionalmente movida exclusivamente a combustíveis fósseis. $\mathrm{O}$ que também está a mudar. Verifica-se um movimento de automatizaçâo e eletrificaçăo do setor. Os veículos elétricos já năo săo apenas protótipos e, por razôes de descarbonizaçăo (evitando escândalos relacionados com falsas emissóes de baixo carbono), incentivos fiscais, inovaçấo e crescimento do apetite de mercado por carros mais verdes, a procura pelos veículos elétricos está a crescer, o que significa maior consumo de energia elétrica e necessidade da existência de mais carregadores de veículos elétricos.

A transiçấo energética ocorre, portanto, num contexto em que a produçăo e comercializaçăo da energia já foi liberalizada, e é caracterizada nâo só pela prevalência da produçâo elétrica de baixo carbono, mas também por uma nova realidade ao nível dos sistemas energéticos, marcados pela digitalizaçâo (VASCONCELOS, 2017).

\section{DESAFIOS NO NOVO CONTEXTO}

As novas realidades trazidas pela transiçâo energética, que está em curso, acarretam inúmeros desafios, inclusivamente possíveis disrupçôes, que importa acautelar.

Desde logo, num contexto de produçăo distribuída, por natureza intermitente, é preciso náo esquecer que o setor elétrico mantém-se essencialmente network dependent para a generalidade dos consumidores e a ligaçăo física entre a procura e a oferta tem de ser garantida de forma instantânea (balancing) ${ }^{26}$, mesmo em casos de peak demand, num quadro de armazenagem muito limitada e de possíveis congestionamentos (bottlenecks) ${ }^{27}$.

Esta realidade gera um desafio acrescido de flexibilidade e resiliência para o sistema elétrico (DOBBENI; GLACHANT; VINOIS, 2017), uma vez que tipicamente as novas fontes săo intermitentes. Isto é, as novas fontes de energia, tais como a solar e a eólica, por natureza, năo săo despacháveis nos termos em que o eram as fontes convencionais (ex. grande produçâo térmica). O que comporta inevitáveis preocupaçóes com a regularidade e continuidade do serviço e com a segurança do abastecimento (security of supply).

260 que é adensado, num cenário em que a armazenagem de eletricidade está ainda a ser introduzida e assume preços pouco competitivos, pela sazonalidade (diária, semanal e anual) do consumo, bem como pela impossibilidade de armazenamento da eletricidade produzida em grandes quantidades (a preços comportáveis).

27 Cf. SAUTER (2015, pp. 198-202). 
Por sua vez, a menor utilizaçăo das redes elétricas, em volume de energia, acarreta que o custo unitário da utilizaçâo destas possa ser progressivamente maior. O que, no limite, poderia conduzir a um círculo vicioso (death spiral), que teria como principais prejudicados os consumidores com menor capacidade de investimento, por definiçấo, mais totalmente dependentes da rede (consumers divide).

Paralelamente, náo obstante alguns consumidores, com maior capacidade de investimento possam depender menos da rede (ou passar, inclusivamente, a atuar off-grid), o relativo sucesso do veículo elétrico traz novos consumos. O que, por sua vez, para além de trazer inevitáveis necessidades de investimento em edifícios e parques públicos, pode vir a provocar necessidades ao nível das redes elétricas que, como já vimos, têm de estar preparadas para o peak demand.

Noutra perspetiva, as circunstâncias propiciam oportunidades. Os consumidores, com destaque para os industriais, estăo a tornar-se energeticamente mais eficiente, utilizando tecnologias digitais e processos de automatizaçăo que conduzem a poupanças de significativas. E é possível que isso venha a acontecer, inclusivamente, "beyond the plant fence", juntando operaçôes industriais localizadas em sítios diferentes. Paralelamente, os edifícios estâo a tornar-se mais inteligentes com o uso de sensores e algoritmos que programam o serviço de climatizaçăo (IEA, 2017), podendo passar a ser geridos por aggregators. Um menor consumo de eletricidade pode representar uma menor necessidade de investimento para cumprir o (lower) peak load, incluindo um menor investimento na capacidade das redes. Por sua vez, alguns consumidores podem estar disponíveis, mediante uma contrapartida financeira, para consumir menos em horas de escassez. Assim, tanto os prosumers, como os utilizadores de veículos elétricos e outros consumidores que disponham de dispositivos tecnológicos, a prazo, poderăo vir a participar no sistema elétrico atuando de forma ativa no lado da procura (demand-side response). O que permitirá contrariar de forma mais significativa a cultura energética que, tradicionalmente, é centrada marcadamente no lado da oferta (CHEVALIER, 2004, p. 374; SANTOS, 2017, pp. 609-634). O que pode permitir oferecer respostas diferentes no equilíbrio dos mercados (balancing).

As infraestruturas, inclusive as redes elétricas, têm, pois, de ser continuamente adaptadas às novas realidades, procurando melhorar o seu desempenho e níveis de qualidade do serviço, num quadro de um modelo regulatório e tarifário que náo crie barreiras a novos agentes e modelos de negócio.

Para tanto serâo certamente necessários investimentos que promovam a melhor gestăo da rede, favorecendo redes inteligentes, que sejam resilientes e estejam preparadas năo só para responder ao desafio da flexibilidade mas, simultaneamente, às novas questôes de privacidade e cibersegurança geradas pelo uso massivo de software e informaçăo (SAVENIJE, 2013), sem incrementar custos unitários em termos que potenciem o risco de consumers divide.

\section{CONSIDERAÇÕES FINAIS}

A transiçăo energética vem reconfigurar o sistema energético tal como o conhecemos. O previsível fim da "era do petróleo" pode vir a dar lugar a uma maior eletrificaçâo da economia. 
O desenvolvimento tecnológico e os continuados apoios às energias renováveis permitiram que aqui se chegasse. No quadro do energy trilemma, as escolhas dos consumidores e o desenvolvimento dos mercados ditarăo o futuro.

Ao mesmo tempo, a transiçâo energética acarreta múltiplos desafios ao setor elétrico para os quais as respostas possíveis ainda năo estăo testadas. O mundo da energia, e o da eletricidade em particular, văo complexificar-se. Estados, reguladores, agentes e consumidores teráo de ajustar-se no âmbito de um quadro normativo também ele em necessária mudança.

\section{REFERÊNCIAS}

"Royal Dutch Shell and Total flirt with becoming utilities". The Economist, From Mars to Venus, 28 Mar 2018.

ANDOURA, Sami; VINOIS, Jean-Arnold. From the European Energy Community to the Energy Union - a policy proposal for the short and the long term. Series New DecisionMakers, New Challenges. Studies and Reports, Notre Europe, Jacques Delors Institute, January 2015.

ANDRADE, José Carlos Vieira de; MARCOS, Rui de Figueiredo (coord.). Direito do Petróleo. Faculdade de Direito da Universidade de Coimbra, Instituto Jurídico, Coimbra, 2013.

CEER - COUNCIL OF ENERGY EUROPEAN REGULATORS. Renewable Self-Consumers and Energy Communities. CEERWhite Paper series (paper \#VIII).European Commission's Clean Energy Proposals, 27 July 2017.

CEER - COUNCIL OF EUROPEAN ENERGY REGULATORS. Regulatory Aspects of SelfConsumption and Energy Communities. CEERReport, C18-CRM9_DS7-05-03, 25 June 2019.

CHEVALIER, Jean-Marie. Les Grandes batailles de l'énergie: Petit traité d'une économie violente. Collection Folio actuel (n¹11), Gallimard, 2004.

DAINTITH, Terence. "Against 'lex petrolea'". In: The Journal of World Energy Law \& Business, Volume 10, Issue 1, 1 March 2017, pp. 1-13.

DIAS, Jorge Eduardo Figueiredo. "A certificaçăo e a eficiência energética dos edifícios". In: Temas de Direito da Energia, Cadernos O Direito, n. ${ }^{\circ}$ 3, Almedina, 2008.

DOBBENI, Daniel; GLACHANT, Jean-Michel; VINOIS, Jean-Arnold. "The new EU Electricity Package, repackaged as a Six Hands Christmas Wish List...". In: Policy Brief. RSCAS, 2017/27, Florence School of Regulation, Energy, November 2017.

EIKELAND, Per Ove. The Long and Winding Road to the Internal Energy Market Consistencies and inconsistencies in EU policy. FNI Report 8/2004.

EUROPEAN COMPANY LAWYERS ASSOCIATION. Celebrating 30 years of ECLA - About ECLA: a European Lawyers' History, 26 September 2013. 
FATTOUH, Bassam; POUDINEH, Rahmatallah; WEST, Rob. The rise of renewables and energy transition: what adaptation strategy for oil companies and oil-exporting countries?, The Oxford Institute for Energy Studies, May 2018.

GOMES, Carla Amado. “O Regime Jurídico da produçăo de electricidade a partir de fontes de energia renováveis: aspectos gerais". In: Temas de Direito da Energia - Cadernos 0 Direito, n. ${ }^{\circ}$ 3, 2008.

GOMES, Carla Amado; ANTUNES, Tiago. "O Ambiente e o Tratado de Lisboa: uma relaçâo sustentada". In: PIÇARRA, Nuno (coord.). A Uniâo Europeia segundo o Tratado de Lisboa - Aspetos Centrais, Almedina, 2011.

HANCHER, Leigh; HAUTECLOCQUE, Adrien de; SADOWSKA, Małgorzata. “Vienna Forum on European Energy Law: 13 March 2015, Vienna REPORT". In: Renewable Energy Law and Policy Review, vol. 6, no. 2, 2015, pp. III-IX.

HARDIN, Garrett. The Tragedy of the Commons. Science, 1968.

INKPEN, Andrew; MOFFETT, Michael H.. The Global Oil \& Gas Industry: Management, Strategy \& Finance, PennWell, USA, 2011.

INOCÊNCIO, Flávio G. I.. A Organizaçāo dos Países Exportadores de Petróleo: o caso de Angola. Chiado Editora, 2015.

INTERNATIONAL ENERGY AGENCY. Digitalization \& Energy, OECD/IEA, Paris, 2017. JOHNSTON, Angus; BLOCK, Guy. EU Energy Law. Oxford, 2012.

JONES, Christopher. EU Energy Law - Volume I, The Internal Energy Market. Claeys \& Castels, 2006.

LEAL-ARCAS, Rafael; RIOS, Juan Alemany. "The creation of a European Energy Union”. In: European Energy Journal, Volume 5, Issue 3, pp. 24-60, August 2015.

MACNAUGHTON, Joan. Climate-Energy Security Nexus: Role of Policy in Building Resilience to Climate Change. World Energy Council, 4 November 2015.

PÉREZ-ARRIAGA, Ignacio J.. Regulation of the Power Sector. Springer, 2013.

PÉREZ-ARRIAGA, Ignacio; KNITTEL, Christopher. Utility Of The Future: An Mit Energy Initiative Response To An Industry In Transition. Massachusetts Institute of Technology, December 2016.

SANTOS, Filipe Matias. "Contratualizaçăo de Eficiência Energética na Gestăo da Procura, O caso do Plano de Promoçăo da Eficiência no Consumo de Energia Elétrica (PPEC)". In: SILVA, Suzana Tavares da (coord.). Direito da Eficiência Energética. Imprensa da Universidade de Coimbra, 2017. 
SANTOS, Filipe Matias. "Integraçăo Europeia nos Domínios da Energia: da origem à auspiciosa 'Uniăo Energética'”». In: A Regulaçâo da Energia em Portugal 2007-2017, ERSE, p. 33-55, 2016.

SANTOS, Filipe Matias. "The regulatory Challenges of Disruptive Energy Technologies". In: GOMES, Carla Amado; MARQUES, Francisco Paes. The Transformation Of Energy Law Through Technological And Legal Innovations. Conference Proceedings, ICJC/CIDP, Faculdade de Direito da Universidade de Lisboa, p. 51-63, 2018.

SAUTER, Wolf. Public Services in EU Law. Cambridge University Press, 2015.

SAVENIJE, Davide. "The 10 greatest challenges the utility industry faces today". Utility Dive, July 16, 2013.

SILVA, Susana Tavares da. Direito da Energia. Coimbra Editora, 2011.

TRICKS, Henry. "Clean power is shaking up the global geopolitics of energy". The Economist, 15 Mar 2018.

VASCONCELOS, Jorge. "The energy transition from the European perspective". In: MAYOR, Vicente López-Ibor (ed.). Clean Energy Law and Regulation: Climate Change, Energy Union and International. Wildy, Simmonds \& Hill Publishing, London, 2017.

WILGUS, Horace Lafayette. "The Standard Oil Decision: The Rule of Reason". Mich. L. Rev. 9 (1911): 643-70. Disponível em: https://repository.law.umich.edu/cgi/viewcontent. cgi?article $=1924$ \& context=articles.

Recebido em: 25 de agosto de 2019.

Aprovado em: 29 de dezembro de 2019. 